\title{
Resistance to Neurotoxicity in Cortical Cultures from Neuronal Nitric Oxide Synthase-Deficient Mice
}

\author{
Valina L. Dawson, ${ }^{1,2,3}$ Victor M. Kizushi, ${ }^{1}$ Paul L. Huang, ${ }^{4}$ Solomon H. Snyder, ${ }^{2}$ and Ted M. Dawson ${ }^{1,2}$ \\ Departments of ${ }^{1}$ Neurology, ${ }^{2 N e u r o s c i e n c e, ~ a n d ~}{ }^{3 P h y s i o l o g y, ~ T h e ~ J o h n s ~ H o p k i n s ~ U n i v e r s i t y ~ S c h o o l ~ o f ~ M e d i c i n e, ~}$ \\ Baltimore, Maryland 21287, and 4The Cardiovascular Research Center, Massachusetts General Hospital, Boston, \\ Massachusetts 02129
}

In addition to its functions as a neuronal messenger molecule, nitric oxide (NO) has also been implicated in playing a major role in ischemic damage and glutamate neurotoxicity. Using primary cortical cultures from transgenic neuronal NO synthase (NOS) null (nNOS ${ }^{-}$) mice, we definitively establish $\mathrm{NO}$ as a mediator of NMDA and hypoxic neurotoxicity. Neurotoxicity elicited by NMDA is markedly attenuated in nNOS $^{-}$cortical cultures compared with wild-type cultures. The NOS inhibitor nitro-L-arginine is neuroprotective in wild-type but not nNOS cultures, confirming the role of nNOS-derived NO in glutamate neurotoxicity. Confirming that the $\mathrm{nNOS}^{-}$cultures lack NMDAstimulated nNOS activity, NMDA did not stimulate the formation of cGMP in nNOS ${ }^{-}$cultures, but markedly elevates cGMP in wild-type cultures. Both wild-type and $\mathrm{nNOS}^{-}$cultures are sensitive to toxicity induced by NO donors, indicating that pathways stimulated by NO that result in neuronal cell death are still intact in the transgenic mice. Superoxide dismutase is neuroprotective against NMDA and NO neurotoxicity in both wild-type and $\mathrm{nNOS}^{-}$cultures, highlighting the importance of superoxide anion in subsequent neuronal damage. The unknown cellular factors that endow differential resistance to
NMDA neurotoxicity and differential susceptibility to quisqualate neurotoxicity remain intact in the $\mathrm{nNOS}^{-}$cultures, because the response of somatostatin-immunopositive neurons in nNOS ${ }^{-}$cultures to high-dose NMDA and low-dose quisqualate is identical to the response of NOS-iminunopositive neurons in the wild-type cultures. There is no difference in susceptibility to kainate neurotoxicity between nNOS ${ }^{-}$and wild-type cultures and only a modest resistance to quisqualate neurotoxicity, confirming observations that NO-mediated neurotoxicity is associated primarily with activation of the NMDA receptor. The $\mathrm{nNOS}^{-}$cultures are markedly protected from 60 min of combined oxygen-glucose deprivation neurotoxicity compared with wild-type cultures. Wild-type cultures are protected from neuronal cell death by the NMDA receptor antagonist MK-801 and the NOS inhibitor L-nitroarginine methyl ester, but not its inactive stereoisomer D-nitroarginine methyl ester. nNOS cultures were not additionally protected. These data confirm that activation of NMDA receptors and production of NO are primary mediators of neuronal damage after ischemic insult.

Key words: nitric oxide; nitric oxide synthase; glutamate; NMDA; toxicity; ischemia
Nitric oxide (NO) is a biologically important messenger molecule in many diverse tissues throughout the body (Nathan, 1992; Southam and Garthwaite, 1993; Dawson and Snyder, 1994). NO is synthesized from L-arginine by NO synthase (NOS), of which threc isoforms have becn identificd representing the products of three distinct genes: neuronal NOS (nNOS; NOS-1), inducible NOS (iNOS; NOS-2), and endothelial NOS (eNOS; NOS-3) (Marletta, 1993; Dawson and Snyder, 1994; Marletta, 1994). Excess production of NO by nNOS has been implicated in neurotoxicity elicited by glutamate acting through NMDA receptors and in vascular stroke. In primary cerebral cortical cultures, NMDA neurotoxicily is prevented by a variely of NOS inhibitors (Dawson et al., 1991b, 1993a,b, 1995). These results have been

Received Nov. 10, 1995; revised Jan. 30, 1996; accepted Feb. 2, 1996.

V.L.D. is supported by grants from the Public Health Service (NS33142), the American Heart Association, and the Alzheimer's Association. T.M.D. is supported by the Public Health Service (Grants NS01578, NS33277), the American Health Assistance Foundation, Paul Beeson Physician Scholars in Aging Research Program, and International Life Sciences Institute. Some of the authors own stock in (S.H.S. T.M.D.) and are entitled to royalties (S.H.S., T.M.D., V.L.D.) from Guilford Pharmaceuticals, which is developing technology related to the research described in this article. The stock has been placed in escrow and cannot be sold until a date that has been predetermined by The Johns Hopkins University.

Correspondence should be addressed to Dr. Ted M. Dawson, Department of Neurology, The Johns Hopkins University School of Medicine, 600 North Wolfe Street, Pathology 2-210, Baltimore, MD 21287.

Copyright $C 1996$ Society for Neuroscience $0270-6474 / 96 / 162479-09 \$ 05.00 / 0$ independently replicated in numerous culture systems (for review, see Dawson and Snyder, 1994). Some difficulties in replicating these findings may relate to inadequate expression of nNOS neurons in the cultures used (Hewett et al., 1993, 1994). Because NMDA neuroloxicity has been implicated in vascular stroke damage, NOS inhibitors have been evaluated in various stroke models and have provided protection from stroke damage (Carreau et al., 1994; Dalkara et al., 1994; Yoshida et al., 1994). Moreover, mice with deletion of $\mathrm{nNOS}$ (nNOS ${ }^{-}$mice) manifest a substantial reduction in infarct size after permanent focal ischemia (Huang et al., 1994).

$\mathrm{nNOS}^{-}$mice have clarified a number of aspects of NO physiology (Huang et al., 1993). The mutant mice are viable, procreate, and display grossly normal locomotor activity (Huang et al., 1993). They possess enlarged stomachs with hypertrophied pyloric sphincters, and thus provide a model for the human disease infantile hypertrophic pyloric stenosis (Huang et al., 1993). Longterm potentiation in hippocampal slices (O'Dell et al., 1994) and long-term depression in cerebellar cultures (Linden et al., 1995) are normal in nNOS $^{-}$animals. Carbon dioxide-induced relaxation of cerebral blood vessels occurs normally in $\mathrm{nNOS}^{-}$mice. This effect of hypercapnia is blocked by NOS inhibitors in wild-type but not in mulant mice, indicating that a non-NO system compensates for the loss of NO (Irikura et al., 1994, 1995). nNOS $^{-}$male mice 
Table 1. Neurotoxicity in wild-type versus $\mathrm{NOS}^{-}$primary cortical cultures after exposure to NMDA, NOS inhibitors, and PARS inhibitors

\begin{tabular}{|c|c|c|}
\hline 'l'reatment & $\begin{array}{l}\text { Wild-type } \\
\% \text { Cell death } \\
\text { Mean } \pm \text { SEM }\end{array}$ & $\begin{array}{l}\text { nNOS }^{-} \\
\% \text { Cell death } \\
\text { Mean } \pm \text { SEM }\end{array}$ \\
\hline $500 \mu \mathrm{M}$ NMDA & $57.1 \pm 3.4$ & $17.4 \pm 2.3^{* *}$ \\
\hline \multicolumn{3}{|l|}{ NOS inhibitor } \\
\hline$+100 \mu \mathrm{M}$ NArg & $17.4 \pm 2.3^{*}$ & $15.6 \pm 3.3$ \\
\hline$+100 \mu \mathrm{M}$ NArg $+1 \mathrm{~mm}$ LArg & $55.8 \pm 3.8$ & $15.0 \perp 4.4$ \\
\hline $500^{-} \mu \mathrm{M}$ NMDA & $61.7 \pm 4.2$ & $20.7 \pm 1.8^{* *}$ \\
\hline \multicolumn{3}{|l|}{ Flavoprotein inhibitor } \\
\hline + 100 nм DPI & $23.4 \pm 3.2^{*}$ & $25.7 \pm 3.2$ \\
\hline \multicolumn{3}{|l|}{ Calcineurin inhibitor } \\
\hline + 100 nм FK506 & $9.3 \pm 3.6^{*}$ & $12.4 \pm 0.9^{*}$ \\
\hline \multicolumn{3}{|l|}{ PARS inhibitors } \\
\hline$+100 \mu \mathrm{M} \mathrm{BZD}$ & $25.5 \pm 3.3^{*}$ & $27.8 \pm 3.2$ \\
\hline$+100 \mu \mathrm{M}$ DHIQ & $24.2 \pm 3.9^{*}$ & $27.0 \pm 3.7$ \\
\hline
\end{tabular}

Data are the means \pm SEM $(n=8-16)$. Each data point represents a minimum of $4000-12,000$ neurons counted. Toxicity was assessed by trypan blue exclusion $20-24$ hr after exposure to experimental conditions, as described in Materials and Methods. Significant overall values were obtained using a chi-square test on all possible combinations. ${ }^{*} p \leq 0.001$ comparing WT/NMDA with WT/NMDA/NArg; WT/ NMDA/NArg/LArg with WT/NMDA/NArg; WT/NMDA with WT/NMDA/DPI; WT/NMDA with WT/NMDA/FKS06; WI/NMDA with W'I/NMDA/BZD; WT/ NMDA with WT/NMDA/DHIQ; and nNOS /NMDA with nNOS ${ }^{-}$/NMDA/FK506. ${ }^{* *} p \leq 0.001$ comparing WT/NMDA with nNOS ${ }^{-} / \mathrm{NMDA}$. There was no significant difference in percent cell death in control conditions between wild-type cultures compared with the nNOS ${ }^{-}$cultures. PARS, Poly(ADP-ribose)synthetase; DPI diphenyleneiodonium; DHIQ, dihydroisoquinoline; NArg, nitro-L-arginine; LArg, L-arginine; BZD, benzamide.

display inappropriate, excessive sexual and aggressive behavior (Nelson et al., 1995).

In the present study, we have used primary cerebral cultures from $\mathrm{nNOS}^{-}$mice to clarify the role of $\mathrm{NO}$ in neurotoxicity. We demonstrate a loss of neurotoxicity in response to NMDA stimulation and ischemic insult of combined oxygen-glucose deprivation.

\section{MATERIALS AND METHODS}

Cell culture. Primary cortical cell cultures were prepared from gestational day 16 fetal mice in a procedure modified from that described previously (Dawson et al., 1991b, 1993b). Briefly, the cortex is dissected and the cells dissociated by trituration in modified Eagle's medium (MEM), $20 \%$ horse serum, $25 \mathrm{~mm}$ glucose, and $2 \mathrm{~mm}$ L-glutamine after a $30 \mathrm{~min}$ digestion in $0.027 \%$ trypsin/saline solution. The cells are plated on $15 \mathrm{~mm}$ multiwell plates coated with polyornithine. Four days after plating, the cclls are treated with 5-fluoro-2-deoxyuridine for $3 \mathrm{~d}$ to inhibit proliferation of non-neuronal cells. Cells are then maintained in MEM, $10 \%$ horse serum, $25 \mathrm{~mm}$ glucose, and $2 \mathrm{~mm} \mathrm{~L}$-glutamine in an $8 \% \mathrm{CO}_{2}$ humidified $37^{\circ} \mathrm{C}$ incubator. The growth medium is refreshed twice per week, and the neurons are allowed to mature for $14 \mathrm{~d}$ in culture before being used for experiments. Preliminary ontogeny studies in wild-type cultures determined that nNOS is expressed at mature levels by day 14 in culture. Mature levels of nNOS neurons correspond to $1-2 \%$ of total neuronal population (Bredt et al., 1991; Dawson et al., 1993b).

Cytotoxicity. The cells are exposed to neurotoxic conditions as described previously (Dawson et al., 1991b, 1993b). Before exposure, the cells are washed with Tris-buffered control salt solution (CSS) containing (in mM): $120 \mathrm{NaCl}, 5.4 \mathrm{KCl}, 1.8 \mathrm{CaCl}_{2}, 25$ Tris- $\mathrm{HCl}, \mathrm{pH} 7.4$, and 15 glucose. Except for kainate, the exposure solutions containing experimental reagents are administered briefly for $5 \mathrm{~min}$ and then washed off. The cells are then placed in MEM with $21 \mathrm{mM}$ glucose and returned to the incubator overnight. Exposure to kainate is performed in MEM with 21 $\mathrm{mm}$ glucose overnight in the incubator.

The effects of various inhibitors (see Table 1) of NO-dependent cell death pathways were examined in both $\mathrm{nNOS}^{-}$and wild-type cultures. The concentrations of all the inhibitors used were in the appropriate range of specificity for their respective targets (Dawson et al., 1991b; 1993a,b; Zhang et al., 1994).

Combined oxygen-glucose deprivation is performed as described previously (Kaku et al., 1991; Monyer et al., 1992). The culture media are completely exchanged with deoxygenated, glucose-free Earle's balanced salt solution (EBSS) containing (in $\mathrm{mM}$ ): $116 \mathrm{NaCl}, 5.4 \mathrm{KCl}, 0.8 \mathrm{MgSO}_{4}$, $1 \mathrm{NaH}_{2} \mathrm{PO}_{4}$, and $0.9 \mathrm{CaCl}_{2}$, bubbled with $5 \% \mathrm{II}_{2} / 85 \% \mathrm{~N}_{2} / 5 \% \mathrm{CO}_{2}$. The cultures are kept in an anaerobic chamber containing the gas mixture $5 \%$ $\mathrm{H}_{2} / 85 \% \quad \mathrm{~N}_{2} / 5 \% \quad \mathrm{CO}_{2}$ maintained at $37^{\circ} \mathrm{C}$. Combined oxygen-glucose deprivation is terminated by removal of the cultures from the chamber and replacement of the EBSS solution with oxygenated MEM containing $21 \mathrm{~mm}$ glucose. The cultures are returned to a humidified incubator containing $5 \% \mathrm{CO}_{2}$ and atmospheric oxygen at $37^{\circ} \mathrm{C}$ overnight.

Toxicity is assayed $20-24 \mathrm{hr}$ after exposure to cytotoxic conditions by trypan blue exclusion ( $0.4 \%$ trypan blue in CSS) as described previously (Dawson et al., 1991b, 1993b). Both live cells (cells that exclude trypan blue and are raised dots under Hoffman modulation optics) and dead cells (cells that take up trypan blue and are flat under Hoffman modulation optics) are counted. Percent cell death is determined as the ratio of live to dead cells compared with the percent cell death in control wells to account for ccll dcath attributable to mechanical stimulation of the cultures. At least two separate experiments using four separate wells is performed with a minimum of $4000-12,000$ neurons counted per data point. The data are collected and counted by an observer blinded to the treatment protocol.

Data are analyzed with a one-way ANOVA and the Student-NewmanKeuls multiple comparison test or the Student's $t$ test for independent means.

cGMP assays. For determination of cGMP, the cultures are washed with CSS followed by a $5 \mathrm{~min}$ exposure to experimental solutions containing $100 \mu \mathrm{M}$ 1-methyl-3-isobutylxanthine (IBMX), a phosphodiesterase inhibitor. The experiment is terminated by the addition of $15 \%$ ice-cold trichloroacetic acid. The samples are extracted with watersaturated ether three times and then cGMP concentrations are determined by radioimmunoassay (RIA) according to the manufacturer's instructions (Amersham, Arlington Heights, IL).

Immunohistochemistry. Cells were washed three times with CSS and then fixed for $30 \mathrm{~min}$ at room temperature in freshly depolymerized $4 \%$ paraformaldehyde $/ 0.1 \mathrm{M}$ phosphate buffer. The cells were washed once in Tris-buffered saline (TBS) containing $50 \mathrm{~mm}$ Tris- $\mathrm{HCl}, 1.5 \% \mathrm{NaCl}, \mathrm{pH}$ 7.4. The cultures were permeabilized with $0.2 \%$ Triton X-100/TBS for 5 $\mathrm{min}$ and then blocked with $4 \%$ normal goat serum (NGS) $/ 0.1 \%$ Triton $\mathrm{X}-100 / \mathrm{TBS}$ for $1 \mathrm{hr}$. The cells were incubated overnight at $4^{\circ} \mathrm{C}$ in affinitypurified anti-nNOS antibodies or anti-somatostatin antibodies (Dawson et al., 1991a, 1993a; Huang et al., 1993). The cells were rinsed three times in TBS, 10 min each rinse, followed by incubation in biotin-conjugated secondary antibody (goat anti-rabbit) $/ 1.5 \%$ NGS/0.1\% Triton X-100/TBS for $1 \mathrm{hr}$ at room temperature. The cells were again rinsed three times for 10 min each in TBS. The stain was developed with a substrate solution containing $0.01 \% \mathrm{H}_{2} \mathrm{O}_{2} / 0.5 \mathrm{mg} / \mathrm{ml}$ diaminobenzidine/TBS. The stain was terminated by rinsing the cells in $0.02 \%$ sodium azide/TBS. Photomicrographs were made, and all NOS-positive and somatostatin-positive cells were counted in each well with an inverted Zeiss Axioplan microscope (Thornwood, NY).

Materials. FK506 was a generous gift from Fujisawa Pharmaceuticals (Tokyo, Japan). 3-Morpholino-sydnonimine hydrochloride (SIN-1) was a generous gift from Dr. Rainer Henning, Cassella AG (Frankfurt, Germany). Dihydroisoquinoline (DHIQ) was purchased from Aldrich (Milwaukee, WI). Diphenyleneiodonium (DPI) was purchased from Kodak. MK-801 was purchased from Research Biochemicals (Natick, MA). Cell culture media and supplies were purchased from Gibco (Gaithersburg, MD). cGMP RIA kits were purchased from Amersham. Antisomatostatin antibody was obtaincd from Incstar (Stillwater, MN). Diaminobenzidine and the biotin-conjugated goat anti-rabbit secondary antibody were obtained from Vector (Burlingame, CA). All other reagents were obtained from Sigma (St. Louis, MO).

\section{RESULTS}

\section{Cultures from nNOS ${ }^{-}$animals are resistant to NMDA neurotoxicity}

In primary cerebral cortical cultures from fetal rats, exposure to $500 \mu \mathrm{M}$ NMDA kills $60-80 \%$ of the neurons. NMDA-induced cell death is markedly reduced by NOS inhibitors (Dawson et al., 1991b, 1993b). In the present study, we have used primary cortical 

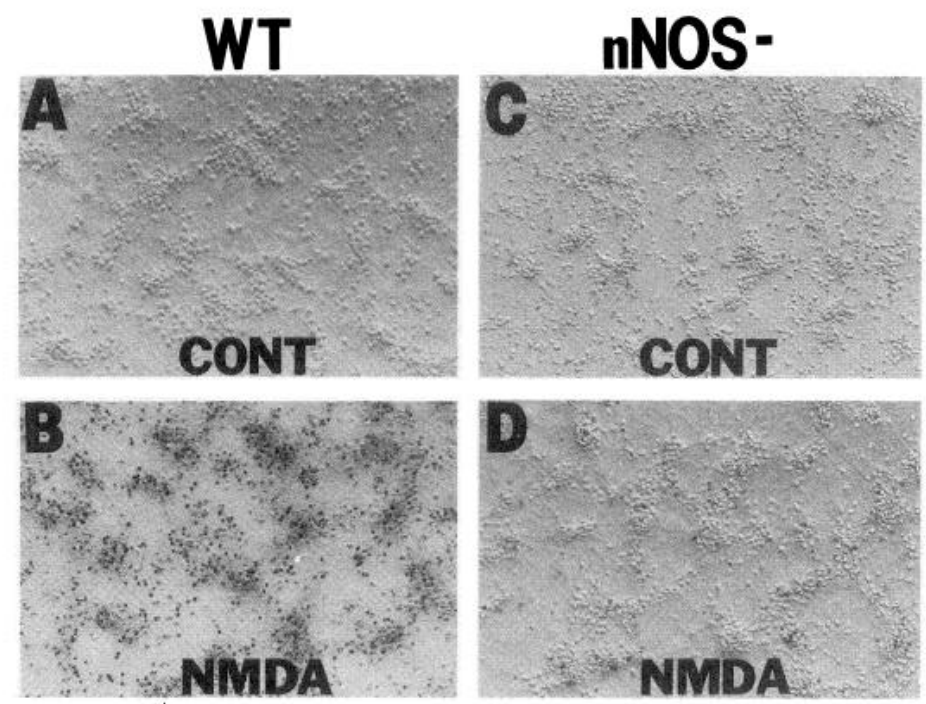

Figure 1. nNOS $^{-}$cultures are resistant to NMDA neurotoxicity. Hoffman modulation photomicrographs of cortical cell cultures $24 \mathrm{hr}$ posttreatment after a $5 \mathrm{~min}$ application of $500 \mu \mathrm{M}$ NMDA. The cultures were treated with $0.4 \%$ trypan blue to stain nonviable cells. Dead cells appear in the photomicrograph as black dots, live neurons are raised cells against the gray background. $A$ and $C$ are control cultures (CONT) from wild-type $(W T)$ and $n N O S^{-}$mice, respectively, that were not exposed to NMDA. $B$ and $D$ are cultures that were exposed for $5 \mathrm{~min}$ to $500 \mu \mathrm{M} \mathrm{NMDA}$. Cultures from $\mathrm{nNOS}^{-}$mice are markedly resistant to NMDA neurotoxicity compared with control cultures. Photomicrographs were taken randomly from culture wells.

cultures from embryonic days 16-17 mice, which are maintained in culture for 2 weeks, exposed to NMDA for $5 \mathrm{~min}$, and evaluated for toxicity $24 \mathrm{hr}$ later. The $80 \%$ cell death elicited by $500 \mu \mathrm{M}$ NMDA in wild-type cultures is almost completely abolished in nNOS $^{-}$cultures (Fig. 1). There remains a very small residual amount of cell death elicited by NMDA in the $\mathrm{nNOS}^{-}$cultures, which displays a dose-response relationship with maximal effects at $500 \mu \mathrm{M}$ NMDA (Fig. 2). At all NMDA concentrations, cell death is profoundly reduced.

Previously, we showed that NMDA neurotoxicity can be blocked by inhibiting NOS at both the catalytic site as well as regulatory sites distinct from the catalytic site. Nitro-L-arginine competes with L-arginine for the catalytic site and blocks synthesis of NO. As reported previously in rat cultures (Dawson et al., 1991b, 1993b), nitro-L-arginine blocks NMDA-induced neurotoxicity in cultures from wild-type mice, and its protective effect is reversed by L-arginine (Table 1). The much diminished neurotoxicity in the $\mathrm{nNOS}^{-}$cultures is decreased slightly by nitro-Larginine, but this effect is not influenced by L-arginine. DPI inhibits NOS and provides neuroprotection by preventing the shuttling of electrons through the flavin cofactors (Stuehr et al., 1991; Dawson et al., 1993b). The immunosuppressant FK506 also blocks neurotoxicity, possibly by increasing phosphorylated, inactive forms of nNOS (Dawson et al., 1993a). In cultures from wild-type mice, we confirm that DPI and FK506 are neuroprotective against NMDA neurotoxicity (Table 1). DPI has no effect on neurotoxicity in $\mathrm{nNOS}^{-}$cultures, although FK506 does significantly reduce neurotoxicity in the $\mathrm{nNOS}^{-}$cultures. The failure of NOS inhibitors to block NMDA neurotoxicity in $\mathrm{nNOS}^{-}$cultures indicates that the residual toxicity is not derived from generation of NO from other NOS isoforms. Thus, nNOS-derived NO is the sole mediator of neurotoxicity.

We have reported previously that inhibitors of poly(ADP-

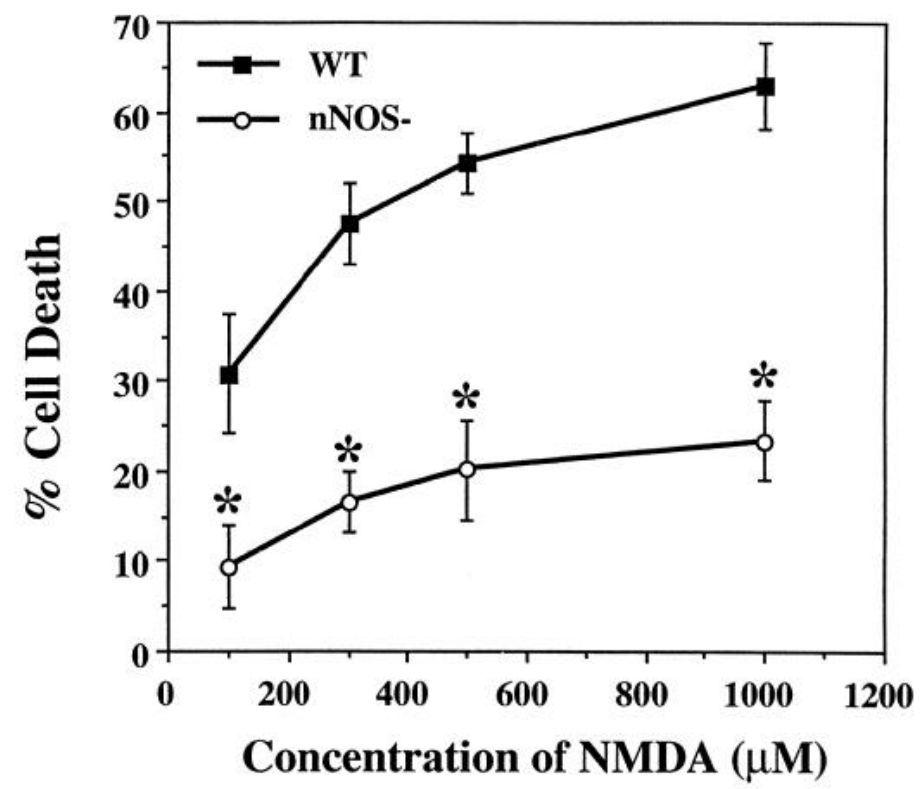

Figure 2. Dose dependence of NMDA neurotoxicity. In primary cortical cultures from wild-type and nNOS ${ }^{-}$mice, NMDA induces neurotoxicity in a dose-dependent manner. However, the neurotoxicity induced in the $n N O S^{-}$cultures is markedly reduced compared with the wild-type (WT) cultures. Each data point represents the means \pm SEM $(n=8-16)$ of at least two separate experiments assayed for toxicity $24 \mathrm{hr}$ after a $5 \mathrm{~min}$ application of NMDA. Each data point represents a minimum of 400012,000 neurons counted. Significance was determined by the Student's $t$ test for paired samples comparing wild-type with nNOS values for each concentration of NMDA. ${ }^{*} p \leq 0.001$.

ribose)synthetase (PARS) prevent NMDA neurotoxicity in rat cortical cultures (Zhang et al., 1994). PARS is activated by DNA fragments generated by NO damage to DNA (Berger, 1985; Lautier et al., 1993). The protective effect of PARS inhibitors implies that DNA damage by NO is a mediator of NMDA neurotoxicity (Zhang et al., 1994). In wild-type primary mouse cultures, the structurally distinct PARS inhibitors benzamide and DHIQ both prevent NMDA neurotoxicity. In nNOS ${ }^{-}$cultures (Table 1), the PARS inhibitors cause a slight but statistically insignificant increase in cell death. The inability of PARS inhibitors to block NMDA neurotoxicity in nNOS cultures indicates that NO is the major activator of PARS in NMDA neurotoxicity in wild-type cultures. The lack of additional neuroprotection by the various inhibitors used in this study could conceivably be because of the small amount of residual toxicity in the nNOS cultures, which is not sufficient to activate these pathways.

In rat cortical cultures, we showed that NOS inhibitors are most effective in protecting against NMDA toxicity with only modest protective effects in cultures from different brain regions against toxicity induced by the non-NMDA receptor agonists quisqualate or kainate (Dawson et al., 1993b). Cortical cultures from nNOS animals are not protected against kainate toxicity and are only modestly protected against quisqualate neurotoxicity. The modest protection observed against quisqualate may be attributable to the secondary activation of NMDA receptors by quisqualate. However, in the same experiments, these cultures are profoundly resistant to NMDA neurotoxicity (Fig. 3).

\section{NMDA stimulation of cGMP formation is abolished in nNOS ${ }^{-}$cultures}

The activation of guanylyl cyclase by NO to increase cGMP formation has been studied extensively (Moncada et al., 1989; 


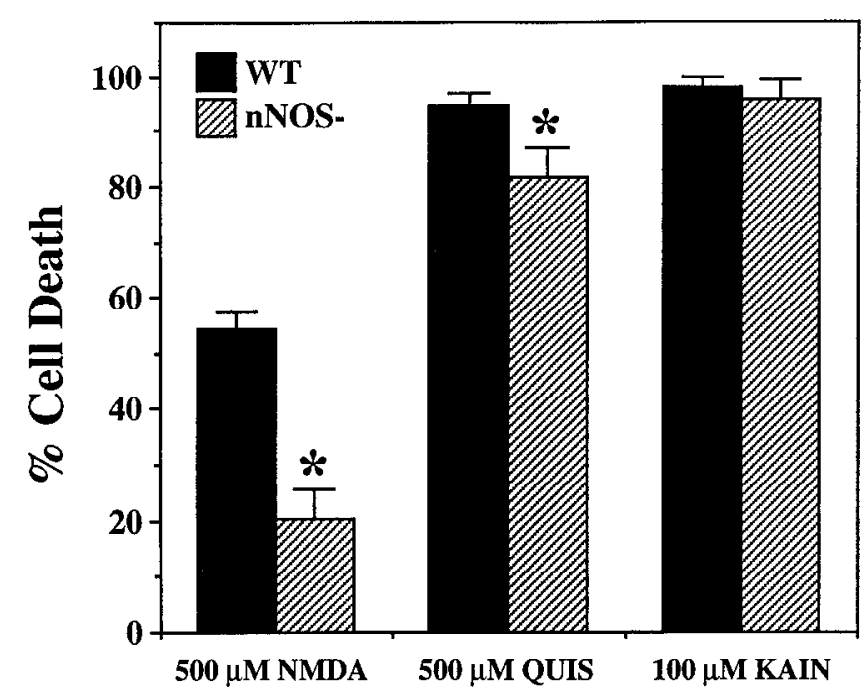

Figure 3. nNOS $^{-}$cultures are resistant to NMDA but not quisqualate or kainate neurotoxicity. Primary cortical cultures from wild-type (WT) and $n N O S^{-}$mice are not resistant to a $24 \mathrm{hr}$ exposure to $100 \mu \mathrm{m}$ kainate $(K A I N)$. nNOS ${ }^{-}$cultures are modestly resistant to neurotoxicily induced by a 5 min application of $500 \mu \mathrm{M}$ quisqualate $(Q U I S)$ and are markedly resistant to a $5 \mathrm{~min}$ exposure to $500 \mu \mathrm{M} N M D A$ compared with the wild-type cultures. Each data point represents the means \pm SEM $(n=$ $8-20$ ) of at least two separate experiments. Each data point represents a minimum of 4000-12,000 neurons counted. Significance was determined by the Student's $t$ test for independent means. ${ }^{*} p \leq 0.001$ comparing WT/NMDA with nNOS ${ }^{-} / \mathrm{NMDA}$; WT/QUIS with $\mathrm{nNOS}{ }^{-} / \mathrm{QUIS}$

Ignarro, 1990; Moncada and Higgs, 1993; Southam and Garthwaite, 1993; Garthwaite, 1995; Garthwaite and Boulton, 1995). Recently, we showed that eNOS has discrete localizations in the CNS (Dinerman et al., 1994; O'Dell et al., 1994) and thus could contribute to NO-mediated neurotoxicity. In addition, in the CNS it is unclear whether NO is the sole or primary determinant of endogenous cGMP levels in the brain. The regional distribution of mRNA for guanylyl cyclase parallels that of hemeoxygenase-2 (HO-2) more closely than nNOS (Verma et al., 1993). HO-2 is an enzyme that generates $\mathrm{CO}$, which also stimulates guanylyl cyclase (Verma et al., 1993). Moskowitz. and associates (Huang et al., 1994) observed that basal levels of cGMP in adult $\mathrm{nNOS}^{-}$mice are only $60 \%$ of those of wild-type mice. Moreover, the $30 \%$ increase in cGMP levels elicited by permanent focal ischemia in wild-type animals is absent in $\mathrm{nNOS}^{-}$mice (Huang et al., 1994). Basal cGMP levels in nNOS $^{-}$cultures are only $10 \%$ of those of wild-type preparations (Fig. 4). Although NMDA triples cGMP levels in wild-type cultures, it elicits no effect in nNOS ${ }^{-}$cultures. Thus, eNOS plays no role in NO-stimulated cGMP formation in cortical cultures, consistent with the lack of neuroprotection by NOS inhibitors in $\mathrm{nNOS}^{-}$mice. L-Nitroarginine methyl ester ( 1 -NAMF) completely prevents the NMDA stimulation of cGMP levels in the wild-type preparations, but has no influence in the $\mathrm{nNOS}^{-}$cultures. Interestingly, cGMP levels in the preparations treated with L-NAME plus NMDA are less than half those of basal control values, substantiating the importance of endogenous NO in regulating basal levels of cGMP. The specificity of NOS inhibition is indicated by the failure of D-nitroarginine methyl ester (D-NAME) to block the NMDAinduced increase in cGMP in wild-type cultures.

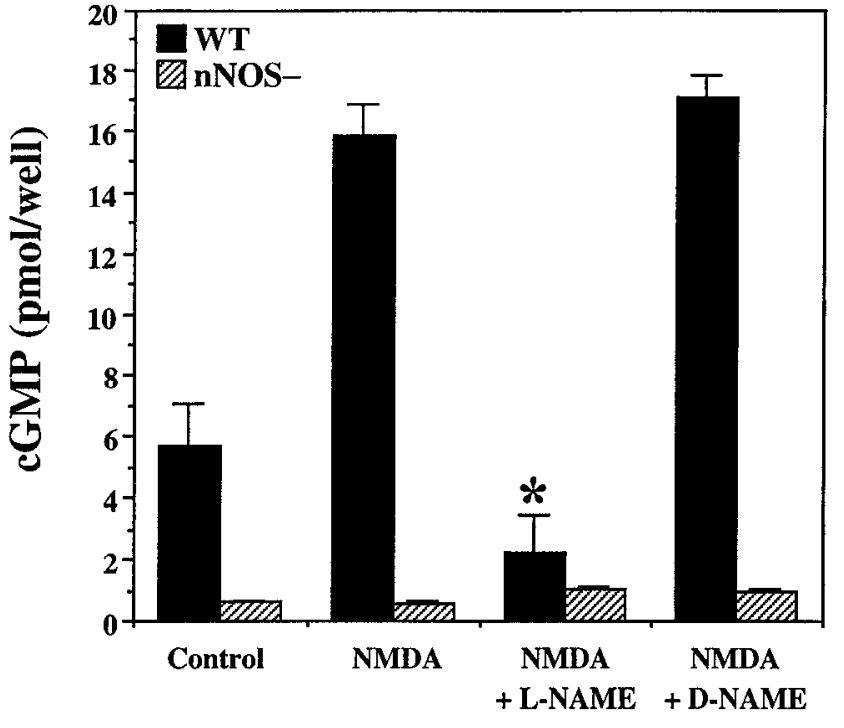

Figure 4. NMDA does not induce cGMP formation in $\mathrm{nNOS}^{-}$cultures. cGMP formation after a 5 min exposure of cortical cultures to $500 \mu \mathrm{M}$ $N M D A$ in the absence or presence of $100 \mu \mathrm{M}$ nitro-L-arginine methyl ester $(L-N A M E)$ or $100 \mu \mathrm{M}$ nitro-D-arginine methyl ester ( $D-N A M E)$. NMDA is effective in tripling the concentration of cGMP in wild-type (WT) but not in ${ }_{n N O S}{ }^{-}$cultures. This induction of cGMP is blocked by L-NAME but not by $D-N A M E$, implicating activation of $\mathrm{nNOS}$ in the wild-type cultures. All experiments were performed in the presence of $100 \mu \mathrm{M}$ IBMX. Data are means $\pm \operatorname{SEM}(n=8)$ of two separate experiments. Significant overall values comparing values within groups were obtained using a chi-square test. ${ }^{*} p \leq 0.001$ comparing WT/NMDA with WT/NMDA/L-NAML.

\section{nNOS/somatostatin neurons are resistant to NMDA neurotoxicity but sensitive to quisqualate neurotoxicity in NOS $^{-}$and wild-type cultures}

In rat cortical cultures, we had demonstrated that neurons expressing $\mathrm{nNOS}$ are resistant to NMDA neurotoxicity to a much greater extent than other neurons (Dawson et al., 1993b). By contrast, the nNOS neurons are more susceptible to quisqualate toxicity than other neurons (Dawson et al., 1993b). In the cerebral cortex, all nNOS neurons also stain for somatostatin, and all somatostatin neurons are also nNOS-positive (Dawson et al., 1991a). In nNOS ${ }^{-}$mice, the density of somatostatin-staining neurons is normal in the cerebral cortex, indicating that although nNOS has been deleted, the neurons remain intact (Huang et al., 1993). Accordingly, we used somatostatin to identify this neuronal population and examine the differential resistance and susceptibility to neurotoxicity of nNOS/somatostatin neurons in cultures from nNOS $^{-}$mice (Fig. 5). Although NMDA kills $\sim 60 \%$ of the total population of neurons from wild-type mice, it kills only $20 \%$ of the nNOS/somatostatin-positive neurons in wild-type cultures. A similar percentage of cell death, 16-20\%, occurs in somatostatin-staining neurons in $\mathrm{nNOS}^{-}$cultures, while the total number of neurons killed is markedly reduced in $\mathrm{nNOS}^{-}$ cultures. The differential susceptibility to quisqualatc of nNOS/ somatostatin-positive neurons in both wild-type and $\mathrm{nNOS}^{-} \mathrm{cul}-$ tures is maintained. Only 15-18\% of the total neuronal population is sensitive to $20 \mu \mathrm{M}$ quisqualate, whereas $>85 \%$ of the nNOS/somatostatin-positive neurons are killed by this low concentration of quisqualate (Fig. 5). These results indicate that the factor(s) that render NOS neurons resistant to NMDA toxicity and sensitive to quisqualate toxicity remain intact in the $\mathrm{nNOS}^{-}$ cultures, and therefore are not likely to be nNOS itself (Fig. 5). 


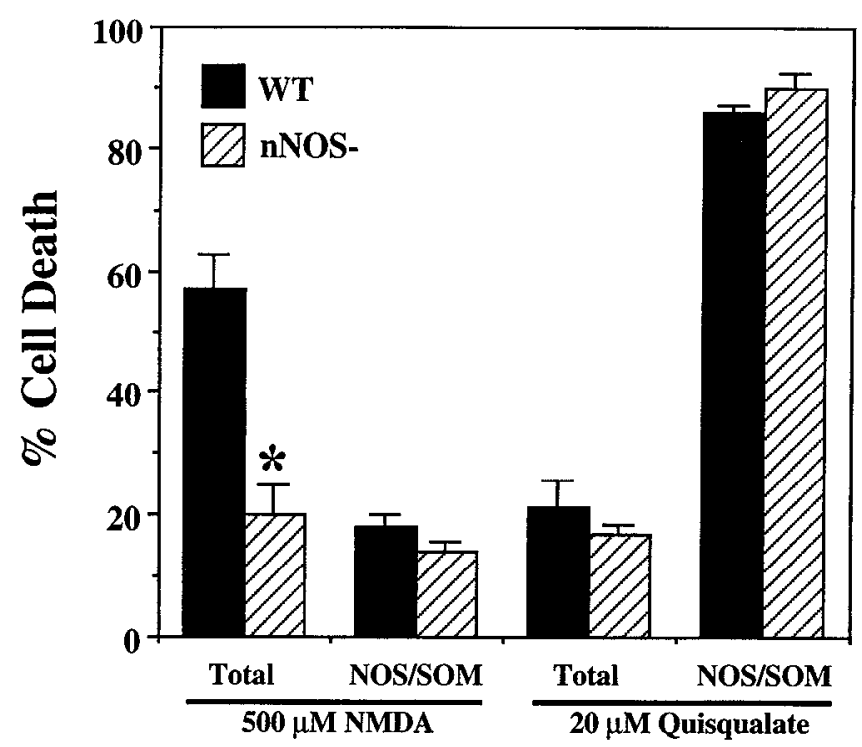

Figure 5. Differential resistance and susceptibility of nNOS/somatostatinpositive neurons. In the ccrcbral cortex, ncurons that cxpress nNOS also express somatostatin and vice versa. In the $\mathrm{nNOS}^{-}$mice, immunoreactivity for somatostatin is used to identify the neurons that express nNOS in the wild-type (WT) mice. Primary neuronal cultures from wild-type (WT) mice and $n N O S^{-}$mice were exposed for 5 min to either $500 \mu \mathrm{M} \mathrm{NMDA}$ or $20 \mu \mathrm{M}$ Quisqualate and $24 \mathrm{hr}$ later were stained by immunohistochemistry for nNOS or somatostatin and by trypan blue for overall (Total) cell death. The number of nNOS/somatostatin-positive (NOS/SOM) neurons were counted per well and compared with the total neuronal cell death determined by trypan blue exclusion. Differential resistance to NMDA and sensitivity to quisqualate of NOS/SOM neurons are maintained in the nNOS" cultures when compared with wild-type cultures. Each data point represents the means \pm SEM $(n=$ 8) of at least two separate experiments. Significance was determined by the Student's $t$ test for independent means comparing wild-type with control cultures within a treatment protocol. ${ }^{*} p \leq 0.001$ comparing total WT/NMDA with total $\mathrm{nNOS}^{-} / \mathrm{NMDA}$.

\section{Superoxide dismutase prevents NMDA and NO neurotoxicity in nNOS $^{-}$and wild-type cultures}

NO neurotoxicity has been suggested to involve a complex of NO and superoxide $\left(\mathrm{O}_{2}^{-}\right)$to form the highly toxic derivative peroxynitrite (ONOO-) (Beckman, 1991, 1994; Radi et al., 1991a,b). Evidence in support of this theory comes from our findings, as well as those of Lipton and collaborators (Dawson et al., 1991b, 1993b; Lipton et al., 1993), that superoxide dismutase (SOD) blocks both NO and NMDA neurotoxicity in rat cortical cultures (Dawson et al., 1991b, 1993b; Lipton et al., 1993). SOD also blocks NMDA neurotoxicity in wild-type mouse cultures (Fig. 6). The greatly attenuated NMD $\Lambda$-induced neurotoxicity in the nNOS $^{-}$cultures is further reduced by $60 \%$ after treatment with SOD. Because NMDA neurotoxicity in the $\mathrm{nNOS}^{-}$cultures does not appear to have an NO component, the protection by SOD suggests that superoxide mediates cell death in the $\mathrm{nNOS}^{-} \mathrm{cul}-$ tures by a mechanism other than $\mathrm{ONOO}_{-}^{-}$, perhaps involving the generation of other oxygen-free radicals and lipid peroxidation (Choi, 1988, 1994; Coyle and Puttfarcken, 1993; Lipton and Rosenberg, 1994; Schulz et al., 1995).

Despite the resistance to NMDA toxicity, NOS $^{-}$cultures remain susceptible to direct damage by NO (Fig. 7). The percentage of cell death elicited by the NO donors sodium nitroprusside (SNP) and SIN-1 is the same in NOS $^{-}$and wild-type cultures. SOD blocks SNP and SIN-1 toxicity to the same extent in wildtype and nNOS ${ }^{-}$cultures, consistent with NO eliciting its toxicity by combining with superoxide to form peroxynitrite.

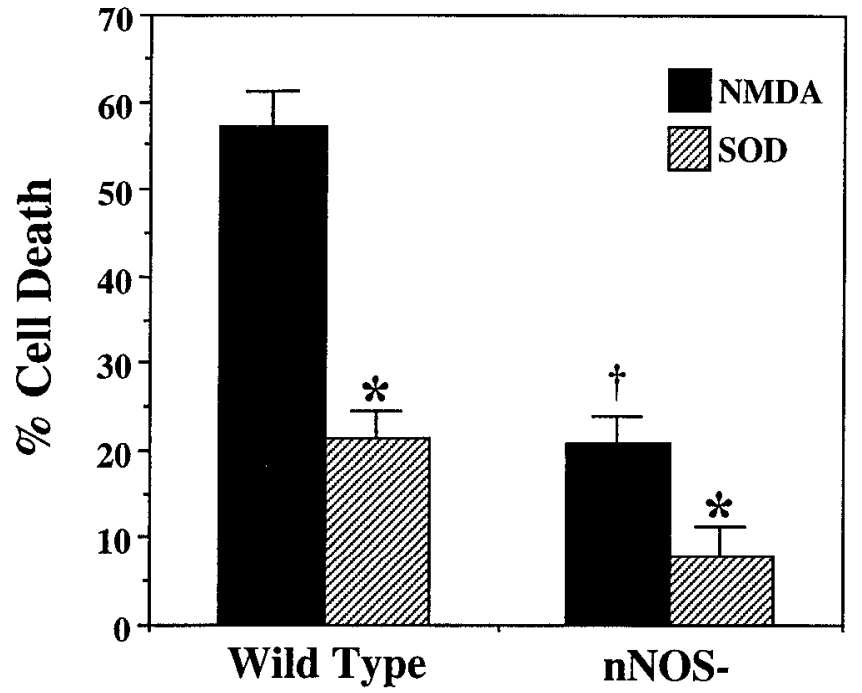

Figure 6. SOD is neuroprotective against NMDA in both wild-type and $\mathrm{nNOS}^{-}$cultures. Primary cortical cultures exposed to $500 \mu \mathrm{M} N M D A$ in the presence of $100 \mathrm{U}$ of $S O D$ are protected against neurotoxicity. Protection induced in wild-type cultures is equivalent to the protection elicited by the knockout of nNOS, suggesting that formation of peroxynitrite is a primary pathway toward cell death. Further protection by SOD is observed in the nNOS ${ }^{-}$cultures, suggesting that there is a parallel but perhaps less active pathway involving oxygen-free radicals. Each data point represents the means 1 SEM $(n-8)$ of at least two separate experiments assayed for toxicity $24 \mathrm{hr}$ after a $5 \mathrm{~min}$ application of NMDA or NMDA and SOD. Each data point represents a minimum of $4000-$ 8000 neurons counted. Significance was determined by the Student's $t$ test for independent means. ${ }^{*} p \leq 0.001$ comparing WT/NMDA with WT/ NMDA/SOD; $\mathrm{nNOS}^{-} / \mathrm{NMDA}$ with $\mathrm{nNOS}^{-} / \mathrm{NMDA} / \mathrm{SOD} ;$ and ${ }^{\dagger} p \leq 0.001$ comparing WT/NMDA with nNOS ${ }^{-} / \mathrm{NMDA}^{-}$

\section{Neurotoxicity elicited by ischemia-glucose deprivation is prevented in NOS $^{-}$mice}

Choi and collaborators (Kaku et al., 1991; Choi, 1993; Goldberg and Choi, 1993) have elegantly shown that neurotoxicity elicited in mouse cortical cultures by combined oxygen-glucose deprivation is blocked by NMDA antagonists. We have replicated these findings in mousc cortical cultures from wild-type animals (Figs. 8, 9). In the wild-type cultures, a major component of neurotoxicity induced by NMDA receptor activation elicited by oxygen-glucose deprivation appears to be through NO, because nitro-L-arginine methyl ester (L-NAME), but not the inactive stereoisomer nitroD-arginine methyl ester (D-NAME), blocks this neurotoxicity (Fig. 9). Additionally, in $\mathrm{nNOS}^{-}$cultures neurotoxicity is markedly attenuated after ischemia-glucose deprivation (Fig. 8). The residual toxicity is not affected by treatment with MK-801, L-NAME, or D-NAME, suggesting that non-NMDA and NO-independent mechanisms are activated (Fig, 9).

\section{DISCUSSION}

Our study using primary neuronal cultures from $\mathrm{nNOS}^{-}$mice clarifies considerably the role of NO in meurotoxicity of cortical neurons. We only assessed cell death $20-24 \mathrm{hr}$ after the initial insults, and the contribution of NO to toxicity that may occur after $24 \mathrm{hr}$ is unknown. Numerous earlier studies had implicated NO as a mediator of NMDA neurotoxicity based on the neuroprotective properties of NOS inhibitors and hemoglobin, which binds NO (Dawson et al., 1991b, 1993b). Besides pharmacological agents targeted to the catalytic site of NOS, such as the arginine derivatives, agents targeted to regulatory elements of NOS were also 


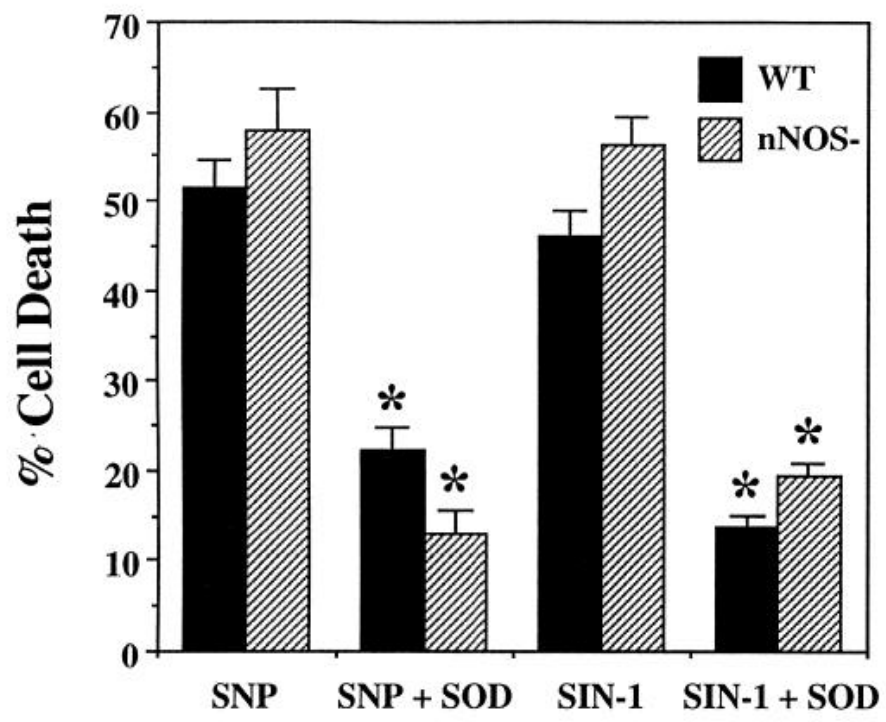

Figure 7. NO is neurotoxic to wild-type and $\mathrm{nNOS}^{-}$cultures. Cultures were exposed to the NO donors [500 $\mu$ M sodium nitroprusside $(S N P)$ or 1 mM 3-morpholino-sydnonimine hydrochloride $(S I N-1)]$ in the presence or absence of $100 \mathrm{U} S O D$. The mechanisms involved in NO-induced cell death remain intact in the $\mathrm{nNOS}^{-}$cultures because the neurotoxicity induced by NO donors is identical to wild-type cultures. SOD is markedly neuroprotective against both NO donors and in both sets of cultures, further implicating the formation of $\mathrm{ONOO}-$ as a major pathway toward neuronal cell death. Each data point represents the means \pm SEM $(n=$ 8 ) of at least two separate experiments assayed for toxicity $24 \mathrm{hr}$ after a 5 min application of NO donors in the presence or absence of SOD. Each data point represents a minimum of $4000-8000$ neurons counted. Significant overall values were obtained using a chi-square test. ${ }^{*} p \leq 0.001$ comparing WT/SNP with WT/SNP/SOD; $\mathrm{nNOS}^{-} / \mathrm{SNP}$ with $\mathrm{nNOS} / \mathrm{SNP} /$ SOD; WT/SIN-1 with WT/SIN-1/SOD; $\mathrm{nNOS}^{-} / \mathrm{SIN}^{-1}$ with nNOS/SIN-1/SOD.

effective in eliciting neuroprotection. The flavoprotein inhibitor diphenyleneiodonium, which blocks the shuttling of electrons by flavin moieties, prevents neurotoxicity (Stuehr et al., 1991; Dawson et al., 1993b). Calmodulin inhibitors of various classes, including calmidazolium (Dawson et al., 1993b) and certain gangliosides (Dawson et al., 1995), prevent neurotoxicity, further confirming that calmodulin is an essential cofactor for NOS activity (AbuSoud and Stuehr, 1993; Abu-Soud et al., 1994). The immunosuppressant drugs FK506 and cyclosporin-A inhibit calcineurin and increase phosphorylated levels of NOS, which results in diminished NOS activity (Dawson et al., 1993a). Both of these agents are also neuroprotective (Dawson et al., 1993a; Sharkey and Butcher, 1994). PARS inhibitors block NMDA neurotoxicity, presumably by preventing the activation of PARS elicited by DNA fragments attributable to damage from NO (Zhang et al., 1994). The overactivation of PARS consumes nicotinamide-adeninedinucleotide and hence ATP, resulting in an irreversible energy depletion (Berger, 1985; Lautier et al., 1993).

NMDA neurotoxicity is thought to be involved in vascular stroke damage, because NMDA receptor antagonists decrease the infarct volume after middle cerebral artery occlusion, as well as other models of stroke (Choi, 1988; Meldrum and Garthwaite, 1990). A role for NO after NMDA receptor activation in stroke damage is supported by reduction of infarct volume with NOS inhibitors (Dawson and Snyder, 1994), as well as the substantial diminution in stroke damage in the brains of $\mathrm{nNOS}^{-}$mice after permanent focal ischemic insult (Huang et al., 1994).

Despite the abundance of data implicating NO in NMDA
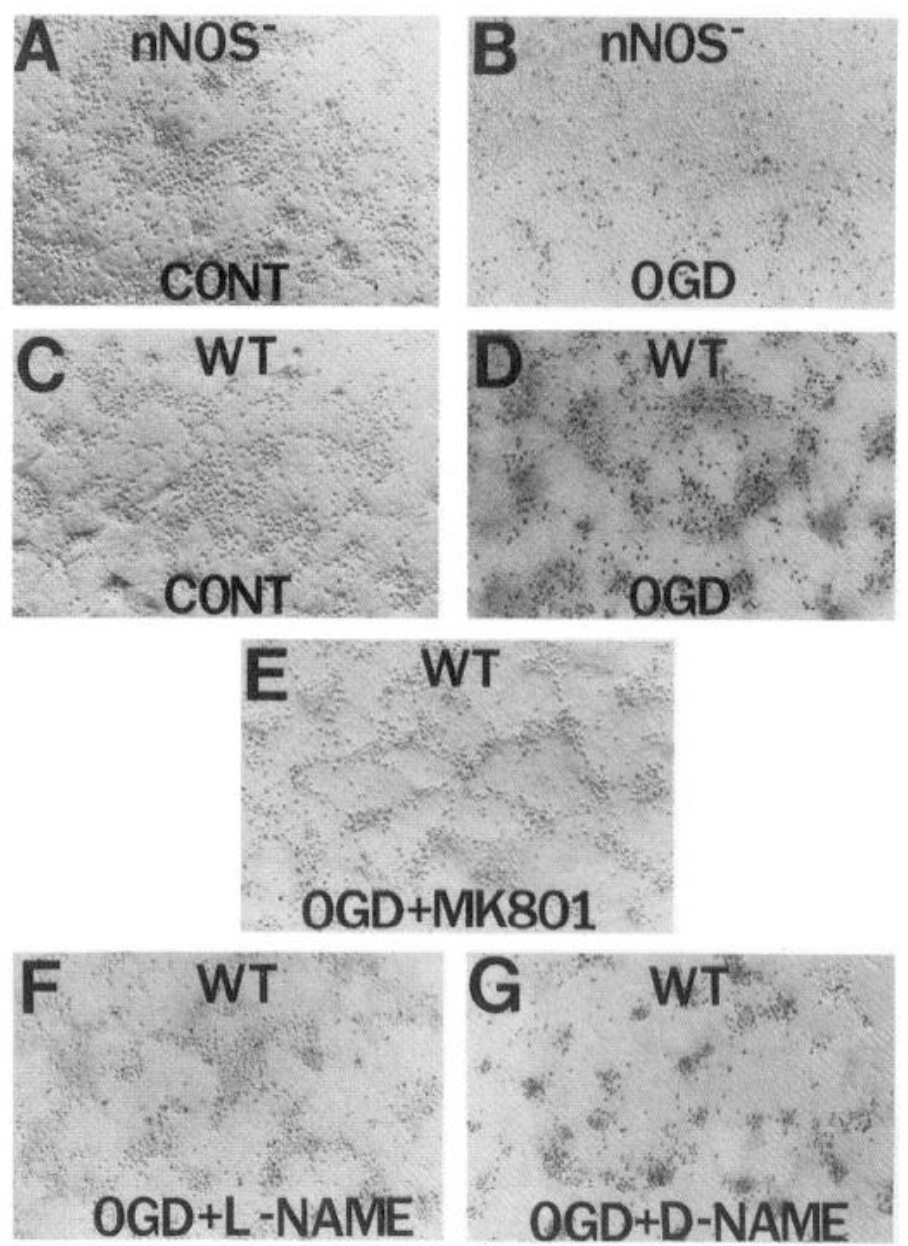

Figure 8. nNOS $^{-}$cultures are spared from ischemic insult. Hoffman modulation photomicrographs of cortical cell cultures $24 \mathrm{hr}$ post-1 hrcombined oxygen-glucose deprivation and after treatment with $0.4 \%$ trypan blue to stain nonviable cells. Dead cells appear in the photomicrograph as black dots, live neurons are raised cells against the gray background. $A, C$, Control cultures (CONT) from $n N O S^{-}$and wild-type (WT) mice, respectively, that were not exposed to combined oxygen-glucose deprivation. $B, D$, Cultures from nNOS and wild-type mice, respectively, that were exposed to $60 \mathrm{~min}$ of combined oxygen-glucose deprivation $(O G D) . E$, Cultures from wild-type mice that were exposed to $60 \mathrm{~min}$ of combined oxygen-glucose deprivation in the presence of $10 \mu \mathrm{M} \mathrm{MK}-801$ $(O G D+M K 801)$. F , Wild-type cultures that were exposed to $60 \mathrm{~min}$ of combined oxygen-glucose deprivation in the presence of $100 \mu \mathrm{M}$ nitro-Larginine methyl ester $(O G D+L-N A M E)$. $G$, Wild-type cultures that were exposed to $60 \mathrm{~min}$ of combined oxygen-glucose deprivation in the presence of $100 \mu \mathrm{M}$ nitro-D-arginine methyl ester $(O G D+D-N A M E)$. Photomicrographs were taken randomly from culture wells under Hoffman modulation optics.

neurotoxicity and stroke damage, there have been concerns that most of these studies are based on the use of drugs that may elicit nonspecific effects. Thus, most NOS inhibitors block all three isoforms. NOS inhibitors administered in vivo inhibit eNOS, raising blood pressure and reducing cerebral blood flow (Dalkara et al., 1994). Arginine analog NOS inhibitors, such as L-nitroarginine, might affect other arginine-dependent phenomena, such as the urea cycle and polyamine biosynthesis. nNOS $^{-}$ animals overcome many of these pharmacological problems. The pronounced attenuation of NMDA neurotoxicity in $\mathrm{nNOS}^{-}$cortical cultures establishes a major role for NO in neurotoxicity.

The profound decline in neurotoxicity in the $\mathrm{nNOS}^{-}$cultures implies that NO may be responsible for as much as $80 \%$ of 


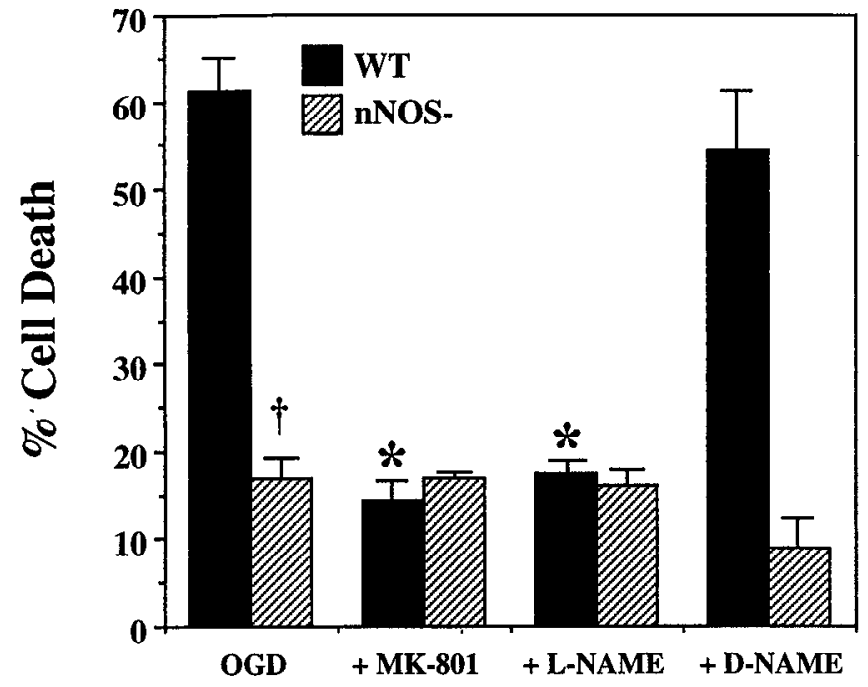

Figure 9. Blockade of NMDA receptors or NOS is neuroprotective against ischemic insult. Primary cortical cultures from wild-type (WT) mice exposed to $60 \mathrm{~min}$ of combined oxygen-glucose deprivation are protected against neurotoxicity by $10 \mu \mathrm{M}$ MK- $801(+M K-801)$ or $100 \mu \mathrm{M}$ nitro-Larginine methyl ester $(+L-N A M E)$. Specificity of NOS inhibition is determined hy the lack of protection from the inactive stereoisomer nitro-Darginine methyl ester $(+D-N A M E)$. Cultures from $n N O S^{-}$mice are resistant to toxicity from $60 \mathrm{~min}$ of combined oxygen-glucose deprivation. MK-801 or L NAME do not further protect nNOS ${ }^{-}$cultures. Each data point represents the means \pm SEM $(n=8)$ of two separate experiments. Each data point represents a minimum of 4000-8000 neurons counted. Significant overall values were obtained using a chi-square test. ${ }^{*} p \leq 0.001$ comparing WT/OGD with WT/MK801; WT/OGD with WT/L-NAME; and ${ }^{\dagger} p \leq 0.001$ comparing WT/OGD with $\mathrm{nNOS}^{-} / \mathrm{OGD}$.

NMDA neurotoxicity. This does not rule out a role for other factors, such as oxygen-free radicals. If two factors act "in series," they may be equally responsible for an event, although blocking out only one of them will abolish the event. For instance, superoxide and NO reacl to form the toxic agent peroxynitrite so that elimination of superoxide with SOD or treating with NOS inhibitors would markedly reduce neurotoxicity. Consistent with this notion are the observations that both SOD and inhibitors of NOS protect against NMDA neurotoxicity (Dawson et al., 1991b, 1993b) and that transgenic mice that overexpress SOD or lack nNOS are protected against focal ischemia (Kinouchi et al., 1991; Chan et al., 1994; Huang et al., 1994). If two factors act "in parallel," then blocking only one of them should partially reduce toxicity. Superoxide may contribute to neurotoxicity independent of NO by interacting with other oxygen-free radicals leading to various types of damage such as lipid peroxidation. This would fit with our observations that SOD markedly reduces neurotoxicity in the $\mathrm{nNOS}^{-}$cultures and that there is superoxide-dependent neuronal cell death in cerebellar granule cells (Lafon-Cazal et al., 1993a,b; Fagni et al., 1994). Choi and collaborators (Kaku et al., 1991; Monyer et al., 1992; Choi, 1993; Goldberg and Choi, 1993; Lynch et al., 1995) have provided evidence for parallel neurotoxic pathways of differing strengths after combined oxygen-glucose deprivation. The NMDA antagonist MK-801 is neuroprotective against $1 \mathrm{hr}$ of combined oxygen-glucose deprivation (Choi, 1993; Goldberg and Choi, 1993). With prolonged combined oxygenglucose deprivation, NMDA antagonists lose their efficacy, whereas non-NMDA antagonists provide protection (Kaku et al., 1991; Choi, 1993). Therefore, a single insult may initiate multiple "parallel" pathways, but blocking the major "parallel" pathway may be protective. Our studies have focused on the initial neurotoxic insults associated with brief combined oxygen-glucose deprivation or brief exposures to excitotoxic agents and suggest that formation of NO from activation of nNOS is a major component toward neuronal cell death induced by excitotoxicity.

Basal cGMP levels in $\mathrm{nNOS}^{-}$cultures are only $10 \%$ of levels in wild-type cultures. Clearly, NO is a major determinant of basal cGMP levels in these cultures, which derive from fetal-neonatal animals. Adult $\mathrm{nNOS}^{-}$mice display only a $40 \%$ decline in cGMP levels (Huang et al., 1994). Moreover, in adult rats nitro-Larginine treatment elicits only moderate reductions in cGMP levels. Thus, cGMP basal levels are determined by endogenous NO to a greater extent in fetal-neonatal animals than in adults. Absolute levels of cGMP are also substantially higher in fetal and neonatal rodent brain than in adult brain. The prominence of NO in determining the elevated levels of cGMP in fetal-neonatal brain may relate to the massive, transient nNOS neuronal system projecting from the cerebral cortex to the thalamus in fetal and neonatal rodents (Bredt and Snyder, 1994). Other factors that determine basal levels of CGMP in adult rodents have not been established. One strong candidate is $\mathrm{CO}$, because its biosynthetic enzyme $\mathrm{HO}-2$ displays similar localizations to guanylyl cyclase in the brain and hemeoxygenase inhibitors lower cGMP levels in some neuronal cultures (Verma et al., 1993).

Differential susceptibility of various neuronal populations to neurotoxicity has been well established. Neurons that stain for NADPH-diaphorase (NDP) are markedly resistant to destruction in Huntington's disease (Ferrante et al., 1985), Alzheimer's disease (Hyman et al., 1992), vascular stroke damage (Choi, 1988, 1990; Uemura et al., 1990), and excitotoxicity in cultures (Koh et al., 1986; Koh and Choi, 1988a,b). We showed that NDP-staining neurons are identical to nNOS neurons (Dawson et al., 1991a), and a major portion of NDP catalytic activity in brain homogenates is accounted for by NOS (Hope et al., 1991). In rat cortical cultures, we established that nNOS-staining neurons are resistant to NMDA neurotoxicity but manifest increased susceptibility to damage by low-dose quisqualate (Dawson et al., 1993b), confirming observations made with NDP (Koh et al., 1986; Koh and Choi, 1988a,b). Identifying nNOS catalytic activity as responsible for NDP in cells that were differentially resistant and susceptible raised the possibility that nNOS might have a role in either the differential resistance or susceptibility of these neurons. Previously, we showed that nNOS neurons, revealed by staining for somatostatin in the cerebral cortex, survive in nNOS ${ }^{-}$animals (Huang et al., 1993). In the present study, we show that the nNOS/somatostatin neurons in the NOS $^{-}$cultures are resistant to NMDA toxicity with the same percentage of cell death of nNOS/somatostatin-positive cells in both the wild-type and nNOS $^{-}$cultures. Because of the substantial resistance of $\mathrm{nNOS}^{-}$ cultures to NMDA neurotoxicity, we cannot make a definitive statement on the resistance of somatostatin neurons to NMDA neurotoxicity in $\mathrm{nNOS}^{-}$mice. These nNOS/somatostatin-positive cells also retain their hypersensitivity to low concentrations of quisqualate. Thus, the unique responses of this subset of neurons to excitatory amino acids is not determined by the expression of nNOS or the ability to form NO. What factors then are responsible for this differential resistance and sensitivity? Recently, using the yeast-two-hybrid technique and other measures of proteinprotein interactions, we identified two novel proteins that are closely associated with nNOS biochemically and display similar localizations in the brain (S. Jaffrey and S. Snyder, unpublished 
observations). Conceivably, these nNOS-associated proteins could mediate this unique differential resistance and sensitivity of nNOS neurons to excitatory amino acid receptor stimulation. NDP (nNOS)-positive cells express cobalt permeant AMPA/kainate receptor channels (Weiss et al., 1994). These calcium-permeant channels probably account for the susceptibility of nNOS neurons to quisqualate and kainate. What accounts for the resistance to calcium influx via NMDA receptor channels and the exquisite sensitivity to calcium influx via AMPA/kainate receptor channels is not known.

Ischemia-glucose deprivation is a useful model of vascular stroke (Choi, 1993). Choi and associates (Kaku et al., 1991; Choi, 1993; Goldberg and Choi, 1993) showed that neurotoxicity after ischemia-glucose deprivation in cultures involves NMDA receptor activation. We confirm their observations that activation of the NMDA receptor plays a primary role in ischemic neurotoxicity, demonstrating in wild-type cultures that MK-801 provides pronounced neuroprotection. We extend these observations to identify the significant role of NO in ischemic insult. We show that wild-type cultures are protected from ischemic insult stereoselectively by the NOS inhibitor L-NAME and that NOSS $^{-}$cultures are markedly resistant to oxygen-glucose deprivation-induced neurotoxicity. In the nNOS ${ }^{-}$cultures, the residual toxicity after $60 \mathrm{~min}$ of ischemia is not further attenuated by MK-801 or L-NAME. These data indicate that neurotoxicity induced by combined oxygen-glucose deprivation is mediated by stimulation of the NMDA receptor, activation of nNOS, and overproduction of NO.

\section{REFERENCES}

Abu-Soud HM, Stuehr DJ (1993) Nitric oxide synthases reveal a role for calmodulin in controlling electron transfer. Proc Natl Acad Sci USA 90:10769-10772.

Abu-Soud HM, Yoho LL, Stuehr DJ (1994) Calmodulin controls neuronal nitric-oxide synthase by a dual mechanism. Activation of intra- and interdomain electron transfer. J Biol Chem 269:32047-32050.

Beckman JS (1991) The double-edged role of nitric oxide in brain function and superoxide-mediated injury. J Dev Physiol 15:53-59.

Beckman JS (1994) Peroxynitrite versus hydroxyl radical: the role of nitric oxide in superoxide-dependent cerebral injury. Ann N Y Acad Sci 738:69-75.

Berger NA (1985) Poly(ADP-ribose) in the cellular response to DNA damage. Radiat Res 101:4-15.

Bredt DS, Snyder SH (1994) Transient nitric oxide synthase neurons in embryonic cerebral cortical plate, sensory ganglia, and olfactory epithelium. Neuron 13:301-313.

Bredt DS, Glatt CE, Hwang PM, Fotuhi M, Dawson TM, Snyder SH (1991) Nitric oxide synthase protein and mRNA are discretely localized in neuronal populations of the mammalian CNS together with NADPH diaphorase. Neuron 7:615-624.

Carreau A, Duval D, Poignet H, Scatton B, Vige X, Nowicki JP (1994) Neuroprotective efficacy of $N$ omega-nitro-L-arginine after focal cerebral ischemia in the mouse and inhibition of cortical nitric oxide synthase. Eur J Pharmacol 256:241-249.

Chan PH, Epstein CJ, Kinouchi H, Kamii H, Imaizumi S, Yang G, Chen SF, Gafni J, Carlson E (1994) SOD-1 transgenic mice as a model for studies of neuroprotection in stroke and brain trauma. Ann N Y Acad Sci 738:93-103.

Choi DW (1988) Glutamate neurotoxicity and diseases of the nervous system. Neuron 1:623-634.

Choi DW (1990) Cerebral hypoxia: some new approaches and unanswered questions. J Neurosci 10:2493-2501.

Choi DW (1993) NMDA receptors and AMPA/kainate receptors mediate parallel injury in cerebral cortical cultures subjected to oxygenglucose deprivation. Prog Brain Res 96:137-143.

Choi DW (1994) Glutamate receptors and the induction of excitotoxic neuronal death. Prog Brain Res 100:47-51.

Coyle JT, Puttfarcken P (1993) Oxidative stress, glutamate, and neurodegenerative disorders. Science 262:689-695.
Dalkara T, Yoshida T, Irikura K, Moskowitz MA (1994) Dual role of nitric oxide in focal cerebral ischemia. Neuropharmacology 33:1447-1452.

Dawson TM, Snyder SH (1994) Gases as biological messengers: nitric oxide and carbon monoxide in the brain. J Neurosci 14:5147-5159.

Dawson TM, Bredt DS, Fotuhi M, Hwang PM, Snyder SH (1991a) Nitric oxide synthase and neuronal NADPH diaphorase are identical in brain and peripheral tissues. Proc Natl Acad Sci USA 88:7797-7801.

Dawson VL, Dawson TM, London ED, Bredt DS, Snyder SH (1991b) Nitric oxide mediates glutamate neurotoxicity in primary cortical cultures. Proc Natl Acad Sci USA 88:6368-6371.

Dawson TM, Steiner JP, Dawson VI, Dinerman .II, Uh1 GR, Snyder SH (1993a) Immunosuppressant FK506 enhances phosphorylation of nitric oxide synthase and protects against glutamate neurotoxicity. Proc Natl Acad Sci USA 90:9808-9812.

Dawson VL, Dawson TM, Bartley DA, Uhl GR, Snyder SH (1993b) Mechanisms of nitric oxide-mediated neurotoxicity in primary brain cultures. J Neurosci 13:2651-2661.

Dawson TM, Hung K, Dawson VL, Steiner JP, Snyder SH (1995) Neuroprotective effects of gangliosides may involve inhibition of nitric oxide synthase. Ann Neurol 37:115-118.

Dinerman JL, Dawson TM, Schell MJ, Snowman A, Snyder SH (1994) Endothelial nitric oxide synthase localized to hippocampal pyramidal cells: implications for synaptic plasticity. Proc Natl Acad Sci USA 91:4214-4218.

Fagni L, Lafon-Cazal M, Rondouin G, Manzoni O, Lerner-Natoli M, Bockaert J (1994) The role of free radicals in NMDA-dependent neurotoxicity. Prog Brain Res 103:381-390.

Ferrante RJ, Kowall NW, Beal MF, Richardson Jr EP, Bird ED, Martin JB (1985) Selective sparing of a class of striatal neurons in Huntington's disease. Science 230:561-563.

Garthwaite J (1995) Neural nitric oxide signalling. Trends Neurosci $18: 51-52$

Garthwaite J, Boulton CL (1995) Nitric oxide signaling in the central nervous system. Annu Rev Physiol 57:683-706.

Goldberg MP, Choi DW (1993) Combined oxygen and glucose deprivation in cortical cell culture: calciunt-dependent and calciumindependent mechanisms of neuronal injury. J Neurosci 13:3510-3524.

Hewett SJ, Corbett JA, McDaniel ML, Choi DW (1993) Inhibition of nitric oxide formation does not protect murine cortical cell cultures from $N$-methyl-D-aspartate neurotoxicity. Brain Res 625:337-341.

Hewett SJ, Csernansky CA, Choi DW (1994) Selective potentiation of NMDA-induced neuronal injury following induction of astrocytic iNOS. Neuron 13:487-494.

Hope BT, Michael GJ, Knigge KM, Vincent SR (1991) Neuronal NADPH diaphorase is a nitric oxide synthase. Proc Natl Acad Sci USA 88:2811-2814

Huang PL, Dawson TM, Bredt DS, Snyder SH, Fishman MC (1993) Targeted disruption of the neuronal nitric oxide synthase gene. Cell 75:1273-1286.

Huang Z, Huang PL, Panahian N, Dalkara T, Fishman MC, Moskowitz MA (1994) Effects of cerebral ischemia in mice deficient in neuronal nitric oxide synthase. Science 265:1883-1885.

Hyman BT, Marzloff K, Wenniger JJ, Dawson TM, Bredt DS, Snyder SH (1992) Relative sparing of nitric oxide synthase-containing neurons in the hippocampal formation in Alzheimer's disease. Ann Ncurol $32: 818-820$

Ignarro LJ (1990) Biosynthesis and metabolism of endothelium-derived nitric oxide. Annu Rev Pharmacol Toxicol 30:535-560.

Irikura K, Maynard KI, Lee WS, Moskowitz MA (1994) L-NNA decreases cortical hyperemia and brain cGMP levels following $\mathrm{CO}_{2}$ inhalation in Sprague-Dawley rats. Am J Physiol 267:H837-H843.

Irikura K, Huang PL, Ma JY, Lee WS, Dalkara T, Fishman MC, Dawson TM, Snyder SH, Moskowitz MA (1995) Cerebrovascular alterations in mice lacking neuronal nitric oxide synthase gene expression. Proc Natl Acad Sci USA 92:6823-6827.

Kaku D $\Lambda$, Goldberg MP, Choi DW (1991) Antagonism of non-NMDA receptors augments the neuroprotective effect of NMDA receptor blockade in cortical cultures subjected to prolonged deprivation of oxygen and glucose. Brain Res 554:344-347.

Kinouchi H, Epstein CJ, Mizui T, Carlson E, Chen SF, Chan PH (1991) Attenuation of focal cerebral ischemic injury in transgenic mice overexpressing $\mathrm{CuZn}$ superoxide dismutase. Proc Natl Acad Sci USA 88:11158-11162. 
Koh JY, Choi DW (1988a) Cultured striatal neurons containing NADPH-diaphorase or acetylcholinesterase are selectively resistant to injury by NMDA receptor agonists. Brain Res 446:374-378.

Koh JY, Choi DW (1988b) Vulnerability of cultured cortical neurons to damage by excitotoxins: differential susceptibility of neurons containing NADPH-diaphorase. J Neurosci 8:2153-2163.

Koh JY, Peters S, Choi DW (1986) Ncurons containing NADPHdiaphorase are selectively resistant to quinolinate toxicity. Science 234:73-76.

Lafon-Cazal M, Culcasi M, Gaven F, Pietri S, Bockaert J (1993a) Nitric oxide, superoxide and peroxynitrite: putative mediators of NMDAinduced cell death in cerebellar granule cells. Neuropharmacology 32:1259-1266.

Làfon-Cazal M, Pietri S, Culcasi M, Bockaert J (1993b) NMDAdependent superoxide production and neurotoxicity. Nature 364:535-537.

Lautier D, Lagueux J, Thibodeau J, Menard L, Poirier GG (1993) Molecular and biochemical features of poly (ADP-ribose) metabolism. Mol Cell Biochem 122:171-193.

Linden DJ, Dawson TM, Dawson VL (1995) An evaluation of the nitric oxide/cGMP/cGMP-dependent protein kinase cascade in the induction of cerebellar long-term depression in culture. J Neurosci 15:5098-5105.

Lipton SA, Rosenberg PA (1994) Excitatory amino acids as a final common pathway for neurologic disorders. $\mathrm{N}$ Engl J Med 330:613-622.

Lipton SA, Choi YB, Pan ZH, Lei SZ, Chen HS, Sucher NJ, Loscalzo J, Singel DJ, Stamler JS (1993) A redox-based mechanism for the neuroprotective and neurodestructive effects of nitric oxide and related nitroso-compounds Nature 364:626-632.

Lynch JJR, Yu SP, Canzoniero LM, Sensi SL, Choi DW (1995) Sodium channel blockers reduce oxygen-glucose deprivation-induced cortical neuronal injury when combined with glutamate receptor antagonists. J Pharmacol Exp Ther 273:554-560.

Marletta MA (1993) Nitric oxide synthase structure and mechanism. J Biol Chem 268:12231-12234.

Marletta MA (1994) Nitric oxide synthase: aspects concerning structurc and catalysis. Cell 78:927-930.

Meldrum B, Garthwaite J (1990) Excitatory amino acid neurotoxicity and neurodegenerative disease. Trends Pharmacol Sci 11:379-387.

Moncada S, Higgs A (1993) The L-arginine-nitric oxide pathway. N Engl J Med 329:2002-2012.

Moncada S, Palmer RM, Higgs EA (1989) The biological significance of nitric oxide formation from $L$-arginine. Biochem Soc Trans 17:642-644.
Monyer H, Giffard RG, Hartley DM, Dugan LL, Goldberg MP, Choi DW (1992) Oxygen or glucose deprivation-induced neuronal injury in cortical cell cultures is reduced by tetanus toxin. Neuron 8:967-973.

Nathan C (1992) Nitric oxide as a secretory product of mammalian cells. FASEB J 6:3051-3064.

Nelson RJ, Demas GE, Huang PL, Fishman MC, Dawson VL, Dawson TM, Snyder SH (1995) Inappropriate sexual and aggressive behavior in mice lacking neuronal nitric oxide synthase. Nature 378:383-386.

O'Dell TJ, Huang PL, Dawson TM, Dinerman JL, Snyder SH, Kandel ER Fishman MC (1994) Endothelial NOS and the blockade of LTP by NOS inhibitors in mice lacking neuronal NOS. Science 265:542-546.

Radi R, Beckman JS, Bush KM, Freeman BA (1991a) Peroxynitrite oxidation of sulfhydryls. The cytotoxic potential of superoxide and nitric oxide. J Biol Chem 266:4244-4250.

Radi R, Beckman JS, Bush KM, Freeman BA (1991b) Peroxynitriteinduced membrane lipid peroxidation: the cytotoxic potential of superoxide and nitric oxide. Arch Biochem Biophys 288:481-487.

Schulz JB, Henshaw DR, Siwek D, Jenkins BG, Ferrante RJ, Cipolloni PB, Kowall NW, Rosen BR, Beal MF (1995) Involvement of free radicals in excitotoxicity in vivo. J Neurochem 64:2239-2247.

Sharkey J, Butcher SP (1994) Immunophilins mediate the neuroprotective effects of FK506 in focal cerebral ischaemia. Nature 371:336-339.

Southam E, Garthwaite J (1993) The nitric oxide-cyclic GMP signalling pathway in rat brain. Neuropharmacology 32:1267-1277.

Stuehr DJ, Fasehun OA, Kwon NS, Gross SS, Gonzalez JA, Levi R, Nathan CF (1991) Inhibition of macrophage and endothelial cell nitric oxide synthase by diphenyleneiodonium and its analogs. FASEB J 5:98-103.

Uemura Y, Kowall NW, Beal MF (1990) Selective sparing of NADPH diaphorase-somatostatin-neuropeptide $\mathrm{Y}$ neurons in ischemic gerbil striatum. Ann Neurol 27:620-625.

Verma A, Hirsch DJ, Glatt CE, Ronnett GV, Snyder SH (1993) Carbon monoxide: a putative neural messenger. Science 259:381-384.

Weiss JH, Turetsky D, Wilke G, Choi DW (1994) AMPA/kainate receptor-mediated damage to NADPH-diaphorase-containing neurons is $\mathrm{Ca}^{2+}$ dependent. Neurosci Lett 167:93-96.

Yoshida T, Limmroth V, Irikura K, Moskowitz MA (1994) The NOS inhibitor, 7-nitroindazole, decreases focal infarct volume but not the response to topical acetylcholine in pial vessels. J Cereb Blood Flow Metab 14:924-929.

Zhang J, Dawson VL, Dawson TM, Snyder SH (1994) Nitric oxide activation of poly(ADP-ribose) synthetase in neurotoxicity. Science 263: 687-689. 